\title{
VARIATIONS OF BRANCHES OF AORTIC ARCH IN NORTH INDIAN POPULATION: A COMPUTED TOMOGRAPHIC STUDY
}

\section{Hema Nagpal *1, P.K. Sharma ${ }^{2}$, Jyoti Chopra ${ }^{3}$, Anit Parihar ${ }^{4}$.}

*1 Senior Resident, Department of Anatomy, University College of Medical Sciences and GTB Hospital, Delhi, India.

2 Professor, Department of Anatomy, King George's Medical University, Lucknow, UP, India.

${ }^{3}$ Professor, Department of Anatomy, King George's Medical University, Lucknow, UP, India.

${ }^{4}$ Professor, Department of Radiodiagnosis, King George's Medical University, Lucknow, UP, India.

\section{ABSTRACT}

Background: The major branches of arch of aorta are the great ways for blood supply to the head and upper limb.The aim of this study was to observe the variations in branching pattern of aortic arch and correlate it embryologically and clinically.

Materials and methods: Computed topographic images of aortic arch region from 110 patients were studied retrospectively. Out of 110 patients, 62 were male and 48 female and were of 3 month to 75 years age. The images were reviewed for normal and variant anatomy of aortic arch and the results were analyzed statistically.

Results: Normal branching pattern of AA was observed in $61.81 \%(n=68)$ of cases. In $27.27 \%(n=30)$ cases a common trunk originated from the aortic arch that gave rise to brachiocephalic trunk and left common carotid artery and second branch was left subclavian artery. In $10.89 \%$ subjects $(n=12)$ left vertebral artery (LVA) was an additional branch apart from three normal branches of AA. LVA had different mode of origin in these cases.

Conclusion: A variant of origin and course of a great vessel arising from the aortic arch is of great clinical value, because lack of knowledge of these variations may lead to serious surgical complications while doing procedures in the superior mediastinum and root of neck.

KEY WORDS: Aortic arch, Computed Tomography, Vascular anatomy, Variation

Address for Correspondence: Dr. Hema Nagpal, Senior Resident, Department of Anatomy, University College of Medical Sciences and GTB Hospital, Delhi, India. Phone: 91-9999072711

E-Mail: hemanagpal30@gmail.com

\begin{tabular}{|c|c|c|}
\hline \multicolumn{3}{|c|}{ Access this Article online } \\
\hline \multirow{2}{*}{ Quick Response code } & \multicolumn{2}{|c|}{$\begin{array}{l}\text { Web site: International Journal of Anatomy and Research } \\
\text { ISSN 2321-4287 } \\
\text { www.ijmhr.org/ijar.htm }\end{array}$} \\
\hline & $\begin{array}{l}\text { Received: } 17 \text { Mar } 2017 \\
\text { Peer Review: } 18 \text { Mar } 2017 \\
\text { Revised: None }\end{array}$ & $\begin{array}{l}\text { Accepted: } 25 \text { Apr } 2017 \\
\text { Published (O): } 31 \text { May } 2017 \\
\text { Published (P): } 31 \text { May } 2017\end{array}$ \\
\hline
\end{tabular}

\section{INTRODUCTION}

Aortic arch is the continuation of ascending aorta, its origin, slightly to the right, is at the level of upper border of the second right sternocostal joint. The arch first ascends diagonally back and to the left over the anterior surface of trachea then back across its left side then finally descends to the left of the fourth thoracic vertebral body, continuing as descending thoracic aorta. The most common branching pattern of the aortic arch (AA) in humans comprises of three great vessels; first, the brachiocephalic trunk (BCT) then the left common carotid artery (LCA) and finally the left subclavian artery (LSA). This pattern occurs in $65-80 \%$ of cases [1]. 
Variations of aortic arch are common. The incidence of variation of the aortic arch branches in different races ranged from $5 \%$ to $35 \%$ [2]. There are several ways to study different variations of aortic arch including MRI, echocardiography and angiography using catheter [3]. Each of the methods carries their own problems: MRI has limited use in several vascular diseases and also non-cooperation of the patients with this technique, Echocardiography has limitations in detecting some diseases including abnormality of big arteries and Digital angiography method is invasive and expensive [4]. T-angiography especially $\mathrm{CT}$ with 64-rows detector is another method used in detecting aorta arch variations. Its non-invasive and inexpensive nature as well as its requiring less time in comparison with other detective techniques can be referred to as its advantages [5]. Taking a three dimensional image from all angles of a unit vascular complex is possible in this method [6]. Knowledge of variations in the branching pattern of the aortic arch is of great importance for patients who have to undergo four vessel angiography, aortic instrumentation, or supra aortic thoracic, head and neck surgery [7]. In the present study we will observe the variations in branching pattern of aortic arch in North Indian population and correlate it embryologically and clinically and also with gender.

\section{MATERIALS AND METHODS}

The study was conducted in Department of Anatomy and Department of Radiodiagnosis, King George's Medical University, UP, Lucknow. The study included 110 patients, out of which 62 were males and 48 females. Age of subjects ranged from 3 months to 75 years across 5 age groups. Efforts were made to include sufficient number of subjects from each age group. Written informed consent from the patients was obtained. The images of patients with previous history of allergy to contrast agent, renal insufficiency, distortion of anatomy of arch of aorta due to any pathology were excluded from this study. CT Angiography was performed on 64-slice multidetector spiral CT scanner. A single unenhanced low-dose scan was first obtained. After that $350 \mathrm{mg} / \mathrm{ml}$ non-ionic contrast medium (Omnipaque) is injected in the antecubital vein at the rate of $5.5 \mathrm{ml} / \mathrm{sec}$. A region of interest was drawn on the aorta at the level of the diaphragm. After an appropriate delay to allow passage of the contrast agent into the renal circulation, a series of thin cuts $(0.9 \mathrm{~mm})$ were obtained throughout the region of aorta. All the images were analysed using Philips DICOM viewer. Number of branches of arch of aorta were indentified in axial, multiplanar reconstructions (MPR) images, and in volume rendered images.

\section{RESULTS}

In the study, normal branching pattern of aortic arch was observed in $61.81 \%(n=68)$ cases (Fig. 1). In $27.27 \%(n=30)$ cases a common trunk originated from aortic arch, that gave rise BCT and LCA and the second branch was LSA (Fig. 2 ). In $10.89 \%$ subjects ( $n=12$ ) LVA was arising from arch of aorta as an additional branch apart from three normal branches. LVA had different mode of origin in these cases. In four cases

Fig. 1:Showing normal branching pattern of arch of aorta in (a) VR 3D image (b) parasagittal MPR image.

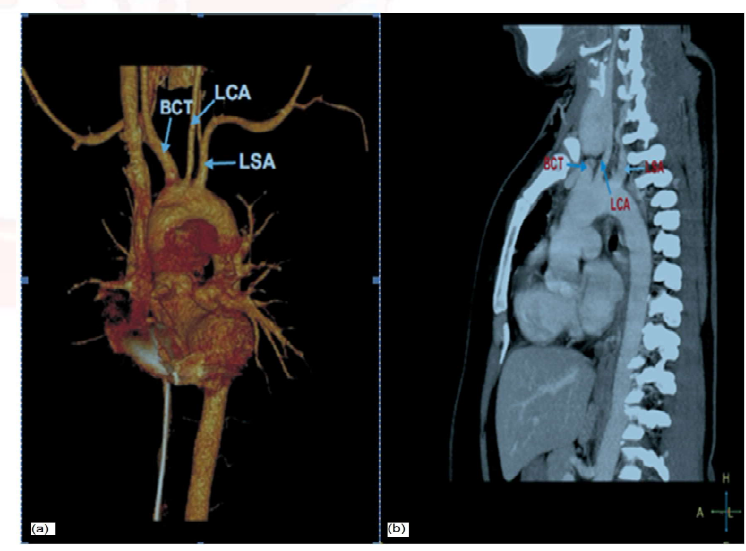

Fig. 2: Showing common trunk (CT1) for brachiocephalic trunk (BCT) and left common carotid artery (LCA) in (a) volume rendered 3D image (b) parasagittal MPR image.
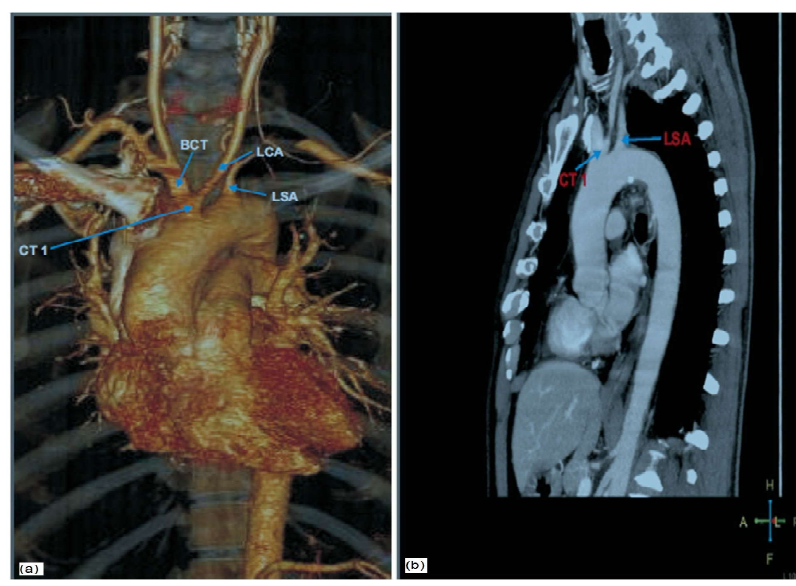
(3.63\%) left vertebral artery had separate origin from arch of aorta just proximal to left subclavian artery, thus aortic arch had four branches in sequence- BCT, LCA LVA, LSA (Fig. 3). Further in four cases (3.63\%) left vertebral artery and left subclavian artery shared a common trunk thus branching pattern was BCT, LCA, CT2 (LVA and LSA) (Fig. 4). and in remaining four cases (3.63\%) two common trunk arose from arch of aorta, first trunk (CT1) gave rise to BCT and LCA while second trunk (CT2) divided into left vertebral artery and left subclavian artery (Fig. 5). Normal branching was the most common pattern in both genders. Next common pattern was the one in which two branches were arising from the aortic arch; a common trunk for brachiocephalic and left common carotid arteries and a left subclavian artery. Statistically, there was no significant association between branching pattern and gender.

Fig. 3: Showing left vertebral artery (LVA) arising directly from the aorta proximal to the left subclavian artery (LSA) in (a)volume rendered 3D \& (b) parasagittal MPR image.

Fig. 4:Showing left vertebral artery (LVA) shared a common trunk with left subclavian artery (LSA) in (a) VR-3D (b) parasagittal MPR image (c) coronal MPR image.
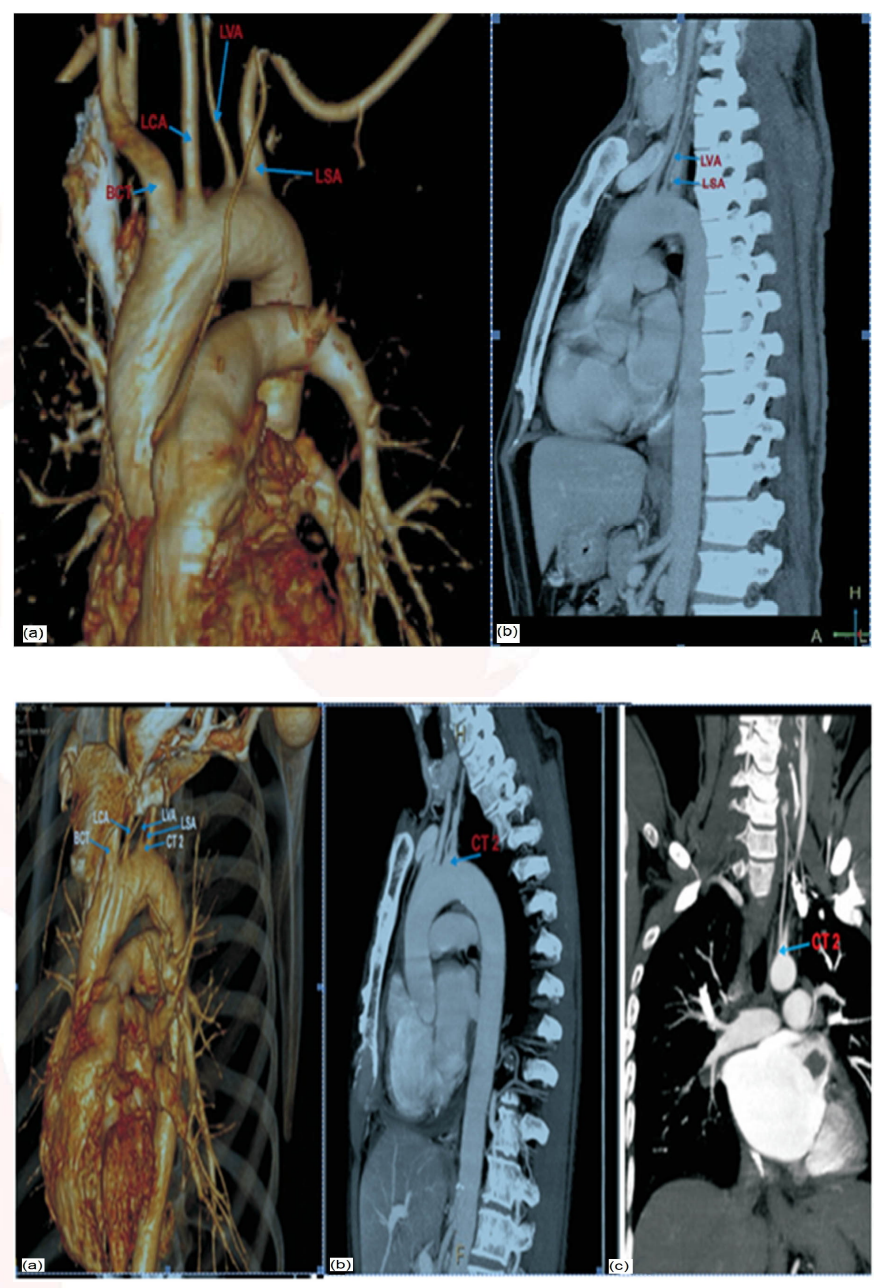

Fig. 5: Showing two common trunk CT1 (common trunk for BCT \& LCA) and CT2 (common trunk for LVA and LSA) in (a) volume rendered 3D image (b) parasagittal MPR.

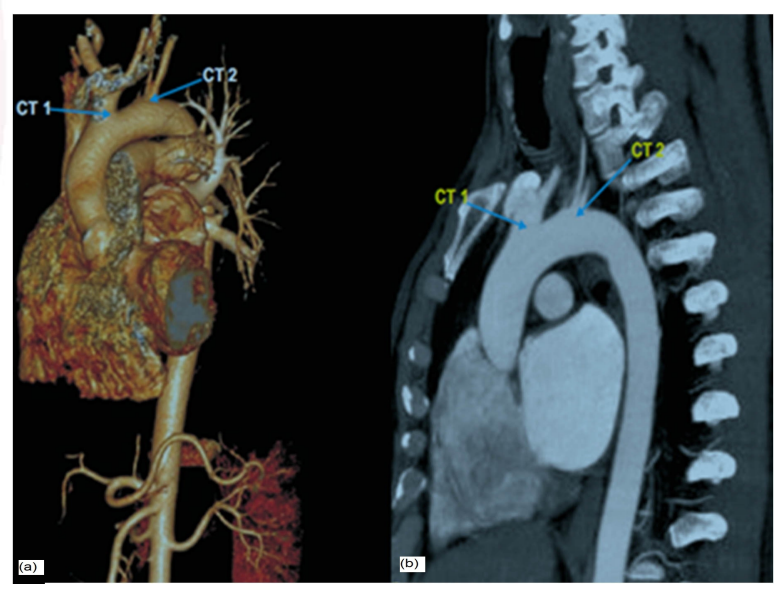




\section{DISCUSSION}

Arterial derangements within the thorax are common, complex and can assume many diverse forms. These derangements in origin and course of main vessels occurring either individually or in combination with other cardiovascular defects are mostly explainable on ontogenic basis, which can be blamed for a myriad of clinically relevant anomalies [8].

In the present study, normal branching pattern of aortic arch was observed in $61.81 \%$ cases. Variant branching pattern was observed in $38.19 \%$ cases, which is higher than that reported in previous studies (Table 2).

The most common variation in branching pattern that was observed was one in which only two branches were arising from aortic arch out of which one was a common trunk(CT1) that gave rise BCT and LCA and other was LSA. This variation has been documented in various studies (Table 2) but in most of them prevalence is quite less as compared to present study (27.27\%). Although Makhanya et al in South African population and Ogeng'o et al in Kenyan population have reported the prevalence of $28.3 \%$ and $25.7 \%$ which is comparable to present study $[9,10]$. The left horn of aortic sac normally forms part of the arch that intervenes between the origins of BCT and LCA. If aortic sac fails to bifurcate into right and left limbs, then LCA will connect to aortic sac directly. This results in a common origin of BCT and LCA The proximal part of the third aortic arch normally gets extended and absorbed into the left horn of aortic sac.

If it gets absorbed into the right horn of the aortic sac, it results in to variable branching pattern of BCT [11]. Inadvertent occlusion of this common trunk may have major ischaemic complications as it supplies both carotids, the right vertebral and subclavian arteries [12]. Further, this variation is associated with cardiac and coronary arterial abnormalities [13].

Next branching pattern observed in present study was in which apart from three normal branches left vertebral artery was also arising directly from arch of aorta, instead of originating from first part of subclavian artery. We reported this variation in $10.89 \%$ cases $(n=12)$. Out of these in four cases (3.63\%) LVA was originating directly from AA between LCA and LSA. Incidence of this variation ranged from $1.7-8 \%$ in various populations(Table2).

Table 1: Branching Pattern and its distribution in males and females.

\begin{tabular}{|c|c|c|c|c|c|c|c|c|c|c|c|}
\hline \multirow[t]{2}{*}{ Variable } & \multicolumn{2}{|c|}{ Normal } & \multicolumn{2}{|c|}{ CT1, LSA } & \multicolumn{2}{|c|}{ BCT, LCA, CT2 } & \multicolumn{2}{|c|}{ BCT, LCA, LVA, LSA } & \multicolumn{2}{|c|}{ CT1, CT2 } & \multirow{2}{*}{$\begin{array}{l}\text { Significance of } \\
\text { difference }\end{array}$} \\
\hline & No. & $\%$ & No. & $\%$ & No. & $\%$ & No. & $\%$ & No. & $\%$ & \\
\hline Overall & 68 & 61.8 & 30 & 27.3 & 4 & 3.6 & 4 & 3.6 & 4 & 3.6 & \multirow{4}{*}{$\begin{array}{c}\chi^{2}=0.183 \\
(d f=4) ; p=0.996\end{array}$} \\
\hline \multicolumn{11}{|l|}{ Gender } & \\
\hline Female & 30 & 62.5 & 12 & 25 & 2 & 4.2 & 2 & 4.2 & 2 & 4.2 & \\
\hline Male & 38 & 61.3 & 18 & 29 & 2 & 3.2 & 2 & 3.2 & 2 & 3.2 & \\
\hline
\end{tabular}

Table 2: Frequency of distribution of branching pattern of aortic arch among various Populations.

\begin{tabular}{|l|c|c|c|c|c|}
\hline \multicolumn{1}{|c|}{ Author (year) } & Population & Type of study & $\begin{array}{c}\text { Variant } \\
\text { branching } \\
\text { pattern (\%) }\end{array}$ & $\begin{array}{c}\text { Aortic arch with } \\
\text { Two branches } \\
\text { (\%) }\end{array}$ & $\begin{array}{c}\text { Vertebral artery } \\
\text { arising directly } \\
\text { from aortic arch } \\
\text { (\%) }\end{array}$ \\
\hline Nelson and Sparks (2001) [14] & Japanese & cadaveric & 5.7 & 1 & 4.1 \\
\hline Ogeng'o etal(2010)[9] & Kenyan & cadaveric & 32.7 & 25.7 & 3.53 \\
\hline Makhanya et al (2004)[10] & South African & $\begin{array}{c}\text { Conventional } \\
\text { angiographic }\end{array}$ & 30 & 28.3 & 1.7 \\
\hline Natsis et al. (2009)[7] & Greek & $\begin{array}{c}\text { Conventional } \\
\text { angiographic }\end{array}$ & 17 & 1.5 & 0.79 \\
\hline Muller,et al (2011)[18] & German & 64-slice CTA & 13.3 & 8 & 4.2 \\
\hline Piyavisetpat et al (2011) [2] & Thai & 64-slice CTA & 11.6 & 5.97 & 4.08 \\
\hline Shakeri et al (2013)[15] & Pakistan & 64-slice CTA & 31.2 & 11.9 & 4.2 \\
\hline Rekha, P. and Senthilkumar, S (2013)[19] & South Indian & cadaveric & 7.28 & 4.5 & 2.72 \\
\hline Current study & North Indian & 64-slice CTA & $\mathbf{3 8 . 1 9}$ & $\mathbf{2 7 . 2 7}$ & $\mathbf{1 0 . 8 9}$ \\
\hline
\end{tabular}


Nelson and Sparks in Japanese population, Shakeri et al in Pakistani population have observed $4 \%$ prevalence which is in consensus with present study $[14,15]$.

Further in four cases (3.63\%) LVA and LSA shared a common trunk. Similar type of variation was also reported by Alsaif \& Ramadan and Nelson and Sparks. Alsaif \& Ramadan reported similar prevalence of this variation as observed in present study but Nelson and Sparks found this variation in only $0.54 \%$ cases $[16,14]$. In remaining four cases (3.63\%) two common trunk arose from arch of aorta, first trunk gave rise to BCT and LCA while second divided into LVA and LSA. Similar variation was observed by Makhanya et al and Suzuki et al but the prevalence was $1.7 \%$ and $0.5 \%$ respectively $[10,17]$. Direct origin of the left vertebral artery from the upper convex surface of the arch of aorta between the origins of the left common carotid and left subclavian arteries may be explained as increased absorption of embryonic tissue of left subclavian artery between the origin of the arch of aorta and the vertebral artery. Knowledge of variations in origin of vertebral artery is important during angiography, thoracic, head and neck surgery [12].

\section{CONCLUSION}

Our data provide information regarding prevalence of variations in aortic arch branching pattern in North Indian population. Cardiovascular, thorax and neck surgeons as well as radiologists and anatomists should be familiar with these variations. Variations in branching pattern of the aortic arch are important during supraaortic angiography or aortic instrumentation and may cause misinterpretation of radiological examination and complications during thoracic and neck surgery.

\section{ABBREVIATIONS}

CTA - Computed tomography Angiography
AA - Aortic arch
BCT - Brachiocephalic Trunk
LCA - Left Common Carotid artery
LSA - Left subclavian artery
LVA - Left vertebral artery
MIP - Maximum Intensity Projection
MPR - Multiplanar Reconstruction

CT1 - Common trunk for BCT and LCA
CT2 - Common trunk for LVA and LSA
VRT - Volume Rendered Technique

\section{Conflicts of Interests: None}

\section{REFERENCES}

[1]. Mligiliche NL, Isaac ND. A three branches aortic arch variant with a bicarotid trunk and a retroesophageal right subclavian artery. Int J Anat Variat 2009;2:11-14.

[2]. Piyavisetpat N, Thaksinawisut P, Tumkosi M. Aortic arch branches' variations detected on chest CT. Thailand Asian Biomedicine 2011;5(6):817-823.

[3]. Sakamoto S, Shibukawa M, Tani I, Araki O, Oki S, et al. Carotid artery stenting in a patient with rightsided aortic arch with an aberrant left subclavian artery. Acta Neurochirurgica 2011;153:2169-2173.

[4]. Milan PB, Nejad DM, Ghanbari AA, Rad JS, Nasrabadi HT, et al. Effects of Polygonum aviculare herbal extract on sperm parameters after EMF exposure in mouse. Pak J Biol Sci 2011;14:720-724.

[5]. Choi HS, Shin DH, Kim KR, Park YA. Preoperative three-dimensional CT angiography to distinguish between an aberrant subclavian artery and a double aortic arch in thyroid surgery: Report of 2 cases. Auris Nasus Larynx 2011;38(1):127-32.

[6]. Muhs BE, Vincken KL, van Prehn J, Stone MKC, Bartels LW, et al. Dynamic cine-CT angiography for the evaluation of the thoracic aorta: Insight in dynamic changes with implications for thoracic endograft treatment. Eur J Vasc Endovasc Surg 2006;32:532-536.

[7]. Natsis KI, Tsitouridis IA, Didagelos MV, Fillipidis AA, Vlasis KG, Tsikaras PD. Anatomical variations in the branches of the human aortic arch in 633 angiogrpahies: clinical significance and literature review. Surg Radiol Anat 2009;31(5):319-323.

[8]. Nathan H, Seidel MR. The association of a retroesophageal right subclavian artery, a rightsided terminating thoracic duct, and a left vertebral artery of aortic origin: anatomical and clinical considerations. Acta Anat (Basel). 1983; 117: 362-373.

[9]. Ogeng'o JA, Olabu BO, Gatonga PM, Munguti JK. Branching pattern of aortic arch in a Kenyan population. J Morphol Sci 2010;27:51-55.

[10]. Makhanya NZ, Mamogale RT, Khan N. Variants of the left aortic arch branches. South Afr Radiol 2004;24(8):10-12.

[11]. Moore KL, Persaud TVN. Cardiovascular system. In: Moore KL, Persaud TVN, editors. The developing human: clinically oriented embryology. 8th ed. Philadelphia: Saunders Elsevier. 2008; 305-6, 316-25.

[12]. Yazar F, Yalcin B, Ozan H. Variation of the aortic arch branches: Two main trunks originating from the aortic arch. Gazi Medical Journal 2003;14(4):181184. 
[13]. Moskowitz WB, Topaz O. The implications of common brachiocephalic trunk associated congenital cardiovascular defects and their management. Cardiol Young 2003;13(6):537-543.

[14]. Nelson ML, Sparks CD. Unusual aortic arch variation: distal origin of common carotid arteries. Clin Anat 2001;14(1):62-65.

[15]. Shakeri A, Pourisa M, Deldar A, Goldust M. Anatomic variations of aortic arch branches and relationship with diameter of aortic arch by 64-row CT angiography. Pakistan J Biol Sci 2013;16: 496-500.

[16]. Alsaif HA, Ramadan WS. An Anatomical Study of the Aortic Arch Variations JKAU: Med Sci 2010;17(2): 37-54.
[17]. Suzuki K, Kazui T, Bashar AH, Yamashita K, Terada H, Washiyama Suzuki T. Total aortic arch replacement in patients with arch vessel anomalies. Ann Thorac Surg 2006; 81(6): 2079-2083.

[18]. Muller M, Schmitz BL, Pauls S, Schick M, Rohrer S, Kapapa T, et al. Variations of the aortic arch a study on the most common branching patterns. Acta Radiol 2011;52:738.

[19]. Rekha P, Senthilkumar S. A study on branching pattern of human aortic arch and its variations in south Indian population. J Morphol Sci 2013; 30(1):1115.

How to cite this article:

Hema Nagpal, P.K. Sharma, Jyoti Chopra, Anit Parihar. VARIATIONS OF BRANCHES OF AORTIC ARCH IN NORTH INDIAN POPULATION: A COMPUTED TOMOGRAPHIC STUDY. Int J Anat Res 2017;5(2.2):38133818. DOI: $10.16965 /$ ijar.2017.188 